\title{
Municipal Mechanic Fatally Injured When Crushed Between a Skid-steer Loader's Frame and Bucket - Massachusetts
}

Release Date: June 23, 2014

Investigation: \# 12-MA-024-01
Massachusetts Department of Public Health Occupational Health Surveillance Program

\section{SUMMARY}

On November 30, 2012, a 55-year-old male municipal mechanic (victim) for a water department was fatally injured while troubleshooting a malfunctioning skid-steer loader. The victim was standing facing the loader between the loader's raised bucket and the frame when the raised bucket came down, crushing the victim against the loader's frame. The victim was found by a co-worker who had entered the garage to check on him. The co-worker immediately called 911 and then called other co-workers from his cell phone. The multiple co-workers and emergency medical workers (EMS) arrived within minutes. EMS transported the victim to a local hospital where he was pronounced dead.

Contributing factors identified in this investigation were that there were no lockout/tagout procedures, the lift arm support device was not installed to prevent the lift arm from lowering, the operator seat bar was engaged while no one was located in the loader's seat, and the victim was working under a raised load.

The Massachusetts FACE Program concluded that to prevent similar occurrences in the future, municipalities should:

- Ensure that safeguards and interlocks are used and are readily accessible, never bypassed;

- Ensure that skid-steer loader lift arm support devices are installed prior to beginning troubleshooting and maintenance tasks that require the lift arm to be in the raised position;

- Ensure that skid-steer loader operator seat bars are only in the lowered position when a worker is seated in the operator's seat;

- Develop, implement and enforce lockout/tagout procedures for skid-steer loader maintenance tasks that include the use of the loader's lift arm support device; and

- Provide work environments for employees that, at a minimum, meet all relevant Occupational Safety and Health Administration (OSHA) regulations and industry accepted standards of practice per the Department of Labor Standards policy. 


\section{INTRODUCTION}

On December 3, 2012, the Massachusetts FACE Program was alerted by the local media that on November 30, 2012, a male municipal mechanic had died from injuries sustained while repairing a skid-steer loader. An investigation was initiated, and on July 23, 2013, a representative from the Massachusetts FACE Program traveled to the municipal water department and met with department representatives to discuss the incident. The police report and death certificate were reviewed during the course of the investigation. Photographs were taken of the incident location and the skid-steer loader.

\section{EMPLOYER}

The employer is a municipal water department for a Massachusetts city with approximately 100,000 residents. The water department has about 160 employees of which three are mechanics. Most of the city's non-management water department employees have union representation, as did the victim.

\section{WRITTEN SAFETY PROGRAMS AND TRAINING}

The department had neither a written safety and health program nor a lockout/tagout program for skid-steer loaders at the time of the incident. Employees of the water department were provided with the 40-hour Hazardous Waste Operations and Emergency Response (HAZWOPER) training when hired. Eight-hour HAZWOPER refresher courses were also provided. Workers employed as equipment operators were required to obtain the Massachusetts Department of Public Safety hoisting license, which is required in Massachusetts to operate skid-steer loaders, but mechanics were not. Regularly scheduled preventive maintenance for equipment, such as oil changes, was performed in-house by the mechanics, and other maintenance tasks were performed when a repair was needed.

\section{VICTIM}

The victim was a 55-year-old male municipal mechanic who had been employed by the city's water department for approximately nine years. The victim was born in Colombia and had lived in the United States for 40 years. The typical work day for the victim was Monday through Friday, 7:30 a.m. to 4:00 p.m., with occasional Saturday work.

\section{INCIDENT LOCATION}

The incident occurred in a storage garage for the water department. The building was a narrow, long building at the edge of the water department's property. The building had multiple overhead garage doors (Figure 1). The build was primarily being used for storage (Figure 2).

\section{EQUIPMENT}

The equipment involved in the incident was a skid-steer loader (Figure 3). The loader was manufactured and purchased in 1996 by the water department. The loader's approximate dimensions with the bucket attachment are 130 inches long, 76 inches high, and 68 inches wide, with a wheel base of 40 inches. The loader has a cab without a door and with one seat for the operator. The key ignition for the loader is located in the upper right hand corner of the cab. The loader is equipped with an operator seat bar interlock. When the operator seat bar is in the raised position, the interlock is engaged preventing the loader from movement (Figure 4). The 
operator seat bar should only be engaged, by placing it in the lowered position, once the operator is seated. There are two controls levers inside the enclosed cab on either side of the seat that control the steering. There are also two pivoting foot pedals that control the position of the loader's lift arm and the tilt of the bucket.

Each lever controls the set of wheels on that side of the loader. When both levers are pushed forward the loader will move forward in a straight line and when both levers are pull back the loader will move in reverse. When just the loader's right lever is pushed in the forward direction, the loader will move forward and turn to the right. When the just right lever is pulled back the loader will move in reverse and turn to the left. The opposite is true for the left lever. The loader will turn to the left when just the left lever is pushed forward and when just the left lever is pulled back the loader will turn to the right. To make the loader turn more quickly with a tighter radius both levers are used. Push the left lever forward and pull the right lever back to turn quickly to the right and push the right lever forward and pull the left lever back to turn quickly to the left.

The loader's right foot pedal controls the tilt of the bucket. Pivoting the right foot pedal back will roll the bucket back towards the loader's cab. Pivoting the right foot pedal forward will roll the bucket forward and dump the contents in the bucket. The left foot pedal controls the loader's lift arm. Pivoting the left foot pedal back will raise the loader's arm and pivoting this pedal forward will lower the loader's arm.

The loader's lift arm wraps around the front of the machine. The lift arm has two hydraulic cylinders located on either side of the loader. The manufacturer equipped the hydraulic cylinder located on the right side of the loader with a lift arm support device (cylinder lock). When the lift arm support device is installed, it will prevent the raised lift arm from being able to be lowered, both intentionally and unintentionally (Figure 5).

Installing the lift arm support device requires two people. First, with the loader's lift arm in the lowered position, the operator enters the cab and sits in the operator's seat with the seat belt fastened and then lowers the seat bar. The co-worker then removes the lift arm support device from its storage position. Then the operator starts the loader's engine and raises the lift arm all the way up. Next, the co-worker installs the lift arm support device over the rod of the hydraulic cylinder. Lastly, the operator lowers the lift arm slowly until the lift arm support device is secured. In this incident, there was some conflicting information about the lift arm support being readily accessible.

\section{INVESTIGATION}

The incident occurred at approximately noon on a Friday. The temperature was 38 degrees Fahrenheit with partly cloudy skies. There was a 10 mile per hour wind making it feel about 30 degrees Fahrenheit outdoors.

On the day of the incident, the skid-steer loader was being used to move some equipment at the water department site. During this task, the operator experienced a problem with the loader where it would not move in either the forward or reverse directions. When this occurred, the 
loader was located inside the water department's storage garage. The operator informed the victim about the issue with the loader and told him that the loader was inside the garage.

The victim went to the storage garage alone and started to troubleshoot why the loader would not move. When the victim was later found by a co-worker, he was crushed between the loader's bucket and cab and the loader was running. The victim was in front of and facing the loader's cab. He was slumped forward into the cab and his head was partially on the operator seat bar that was engaged or in the down position.

The way the victim was found indicates that the loader's lift arm with the bucket attached was raised prior to the incident, and that the victim was working underneath the raised arm without the lift arm support device installed. Also the operator seat bar interlock was engaged or remained engaged while the victim was not located within the loader's seat.

The co-worker who found the victim immediately used his cell phone to call for help. He called other co-workers and called for emergency medical services (EMS). Within minutes multiple co-workers arrived at the storage garage and started to try and free the victim. First they tried to use a floor jack to move the loader's arm and bucket off the victim, but that was unsuccessful. Next, the co-workers jammed a piece of wood against the loader's left pedal and then lifted the loader's arm and bucket to free the victim. Then the co-workers started to use some wood pieces to brace the loader's arm in the raised position. At this point, a few minutes after the calls were placed, EMS arrived. EMS started to attend to the victim and then transported him to a local hospital by ambulance where he was pronounced dead.

\section{CONTRIBUTING FACTORS}

Occupational injuries and fatalities are often the result of one or more contributing factors or key events in a larger sequence of events that ultimately result in the injury or fatality. The Massachusetts FACE team identified the following contributing factors in this incident.

- No lockout/tagout procedures.

- Lift arm support device not installed.

- Operator seat bar engaged with no one in the operator's seat.

- Working under a raised load.

\section{CAUSE OF DEATH}

The medical examiner listed the cause of death as blunt force trauma of the thorax.

\section{RECOMMENDATIONS/DISCUSSION}

\section{Recommendation \#1: Municipalities should ensure that safeguards and interlocks are readily accessible, used and are never bypassed.}

Discussion: The skid-steer loader involved in the incident was manufactured with multiple safeguard and interlocks to prevent unintentional movement and control activation when the operator is not properly seated in the protective cab. When safeguards and interlocks are not 
readily accessible, bypassed or not used, it places the equipment operator and other workers, including maintenance workers, at increased risk of injury from moving parts and crushing forces. ${ }^{1}$ Therefore it should be ensured that all safety devices provided by manufactures are always accessible and properly used.

In this case, at the time of the incident, the loader's lift arm was in the raised position and the lift arm support device was not installed. The loader was running and the operator seat bar was in the down position, which turns off the interlock that allows the loader to move, even though there was no worker seated in the operator's seat. The bypassing of these safeguards combined with the victim working underneath the raised lift arm contributed to the event that lead to the fatal injury sustained by the victim.

\section{Recommendation \#2: Municipalities should ensure that skid-steer loader lift arm support devices are installed prior to beginning troubleshooting and maintenance tasks that require the lift arm to be in the raised position.}

Discussion: During normal operation of a skid-steer loader, the loader's operator should never exit or place any part of their body outside of the cab without lowering the lift arm to the ground first. ${ }^{1}$ In this case, the incident occurred not during normal operation of the loader, but during a troubleshooting/maintenance task where the victim needed the loader's lift arm to remain in the raised position. To safely perform troubleshooting and maintenance tasks requiring the lift arm to be in the raised position, always follow the manufacturer's operating and servicing instructions that state the lift arm support device must be installed as a first step.

Installing the lift arm support device will prevent any movement of the lift arm while it is in the raised position during the troubleshooting/maintenance task. This will allow safe access to the $\mathrm{cab}$ and the area underneath the raised arm. ${ }^{1}$ In addition, the process of installing the lift arm support device should be incorporated into the loader's lockout/tagout procedures (Recommendation \#4).

\section{Recommendation \#3: Municipalities should ensure that skid-steer loader operator seat bars are only in the lowered position when a worker is seated in the operator's seat.}

Discussion: When the victim was found by a co-worker, the skid-steer loader was running, and the operator seat bar was in the down position. As discussed previously, when the operator seat bar is in the down position, the associated interlock is off allowing the skid-steer loader controls to be engaged. The operator seat bar should never be in the down position while there is no one in the operator seat.

In this case, because the operator seat bar was lowered, the interlock that would prohibit the lift arm from moving was not engaged. This allowed the lift arm to lower crushing the victim against the loader's frame/cab. Ensuring that employees only start and engage a loader's controls while seated in the operator's seat, and that the operator seat bar is never in the down 
position when no one is in the operators seat, can prevent the lift arm from unintentional movement that could lead to crushing injuries.

\section{Recommendation \#4: Municipalities should develop, implement and enforce lockout/tagout procedures for skid-steer loader maintenance tasks that include the use of the loader's lift arm support device.}

Discussion: OSHA regulation 29 CFR 1910.147, The control of hazardous energy (lockout/tagout) requires that employers establish procedures for isolating machines and equipment during servicing and maintenance from the input of energy by affixing appropriate locks or tags to energy isolating devices and then blocking and securing any movable part and

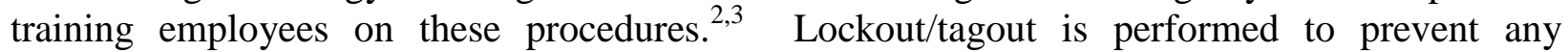
unexpected energization, start-up or release of stored energy such as an unintentionally engaging a control lever or an unexpected hydraulic system failure, that could injure workers during servicing and maintenance of machines and equipment. All forms of energy must be considered, including electrical, hydraulic, pneumatic and mechanical. ${ }^{4}$

In this case, the employer did not have a hazardous energy control program, and therefore did not have procedures for lockout/tagout. At the time of the incident, the victim was troubleshooting/repairing the skid-steer loader and the lift arm was in the raised position, an event that would require implementing lockout/tagout procedures. A specific lockout/tagout procedure should be developed for skid-steer loaders that specifies when lockout/tagout should be implemented and the requirements to properly perform lockout/tagout on each machine. The lockout/tagout procedure for skid-steer loaders should include the use of the manufacturer provided lift arm support device (Recommendation \#2).

Involving employees in the process of inspecting and updating the hazardous energy control program and training is important. The employer should seek input from employees by having employees evaluate the effectiveness and limitations of the hazardous energy control program. Employers should ask employees about techniques involved in completing tasks that require them to expose any part of their bodies to machine and equipment hazards, especially maintenance activities and common procedures that are not typically thought of as part of the everyday operation. Employees who spend the majority of their time operating and performing maintenance tasks on machines and equipment will be able to contribute valuable information that might have been overlooked, and these employees will likely be able to contribute the most information about the effectiveness and limitations of the hazardous energy control program.

A hazardous energy control program with logout/tagout procedures should be part of a more comprehensive Injury and Illness Prevention Program (I2P2) that addresses the full range of potential hazards employees are exposed to while at work. For more information about I2P2 visit the Occupational Safety and Health Administration (OSHA) I2P2 webpage at www.osha.gov/dsg/topics/safetyhealth/. Also attached to the end of this report is a copy of the OSHA I2P2 fact sheet. 


\section{Recommendation \#5: Municipalities should provide work environments for employees that, at a minimum, meet all relevant Occupational Safety and Health Administration (OSHA) regulations and industry accepted standards of practice per the Department of Labor Standards policy.}

Discussion: The federal Occupational Safety and Health Act require private sector employers to provide workplaces that are free from recognized hazards likely to cause death or serious physical harm to employees. While private sector employees are covered by federal OSHA, public sector employees in Massachusetts are not. The Massachusetts Department of Labor Standards (DLS), in accordance with Chapter 149 Section 6, is charged with inspecting public sector workplaces in Massachusetts and determining what procedures and practices are required to protect workers. ${ }^{5}$ As a matter of policy, DLS references OSHA Standards, standards set forth in the MUTCD, as well as other consensus standards such as those developed by the American National Standards Institute (ANSI), in determining whether proper procedures are being followed to protect workers. In this case, adhering to the following OSHA standard may have prevented this incident: 29 CFR 1910.147, The control of hazardous energy (lockout/tagout).

DLS has enhanced efforts to improve health and safety conditions for municipal workers by increasing incident inspections and voluntary technical assistance for municipalities. During an incident inspection if conditions are observed that could cause worker injury or illness, a written warning will be issued by DLS with an order to correct the identified hazards. If the identified hazards are not corrected within the timeframe specified in the written warning, then monetary civil penalties per condition may be issued by DLS to the employer.

\section{REFERENCES}

1. NIOSH [2010]. NIOSH Alert: Preventing Injuries and Deaths from Skid-Steer Loaders. Cincinnati, OH: U.S. Department of Health and Human Services, Public Health Service, Centers for Disease Control, National Institute for Occupational Safety and Health, DHHS (NIOSH) Publication No. 11-128. www.cdc.gov/niosh/docs/2011-128/pdfs/2011-128.pdf

2. Code of Federal Regulations. 29 CFR 1910.147. The control of hazardous energy (lockout/tagout). Washington DC: U.S. Government Printing Office, Office of the Federal Register.

3. NIOSH [1999]. NIOSH Alert: Preventing worker deaths from uncontrolled release of electrical, mechanical, and other types of hazardous energy. Cincinnati, OH: U.S. Department of Health and Human Services, Public Health Service, Centers for Disease Control and Prevention, National Institute for Occupational Safety and Health, DHHS (NIOSH) Publication No. 99-110.

4. NIOSH [2011]. NIOSH Workplace Solutions: Using Lockout and Tagout Procedures to Prevent Injury and Death during Machine Maintenance. Cincinnati, OH: U.S. Department of Health and Human Services, Public Health Service, Centers for Disease Control, National Institute for Occupational Safety and Health, DHHS (NIOSH) Publication No. 11-156. www.cdc.gov/niosh/docs/wp-solutions/2011-156/pdfs/2011-156.pdf 
5. General Laws of Massachusetts, Title XXI, Labor and Industries, Chapter 149: Section 6. Safety devices and means to prevent accidents and diseases generally; fees for structural painting.

Figure 1 - Storage area where incident occurred

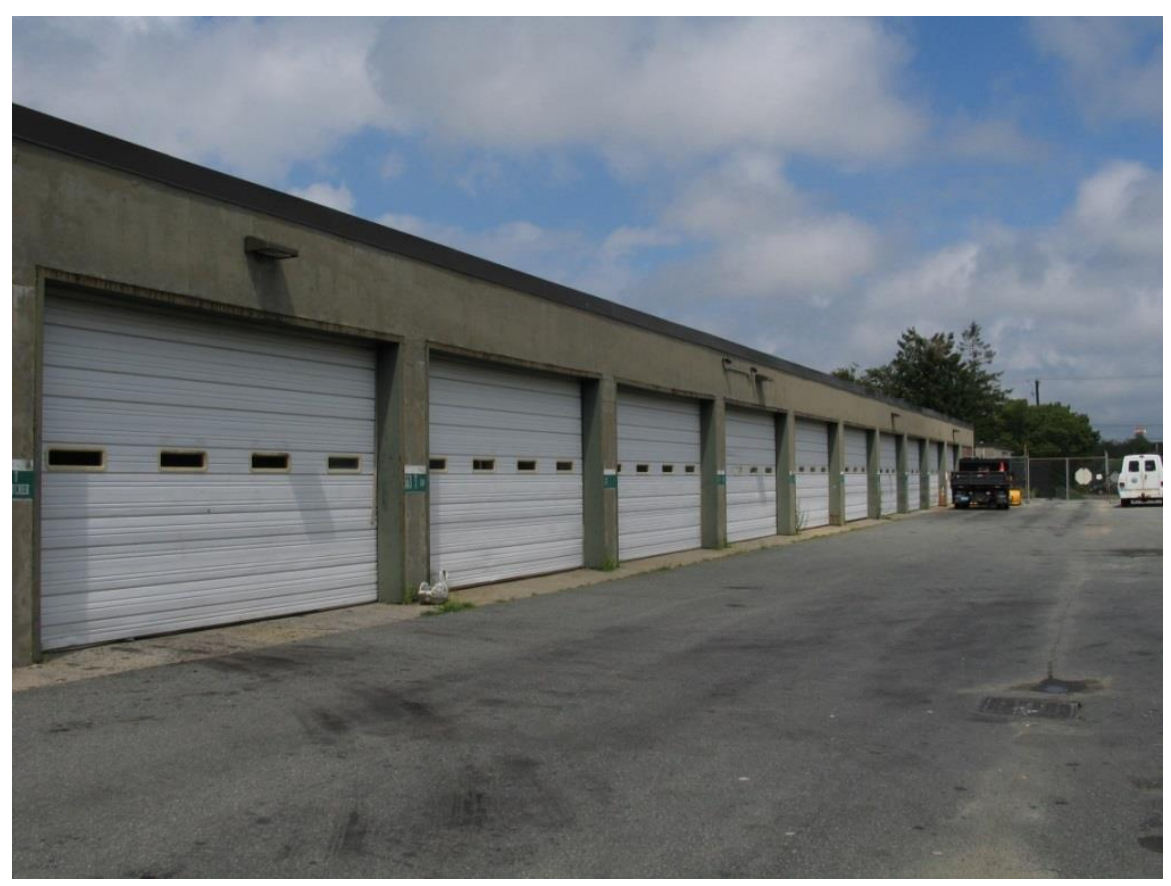

Figure 2 - Incident location with overhead garage door open

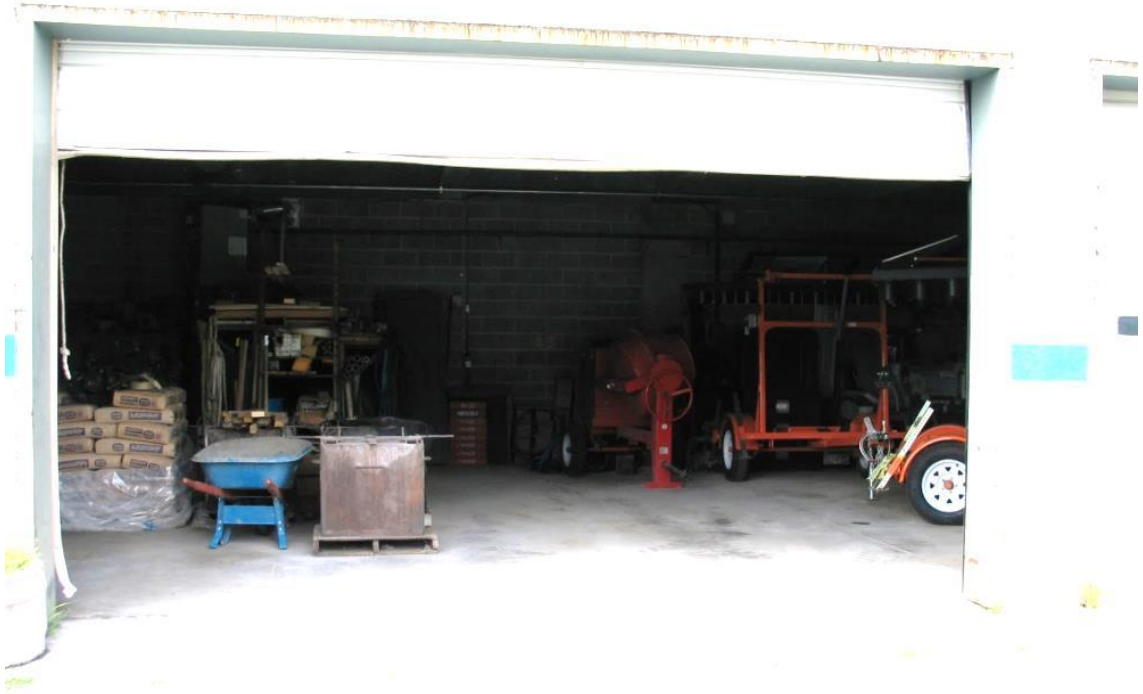


Figure 3 - Skid-steer loader involved in the incident

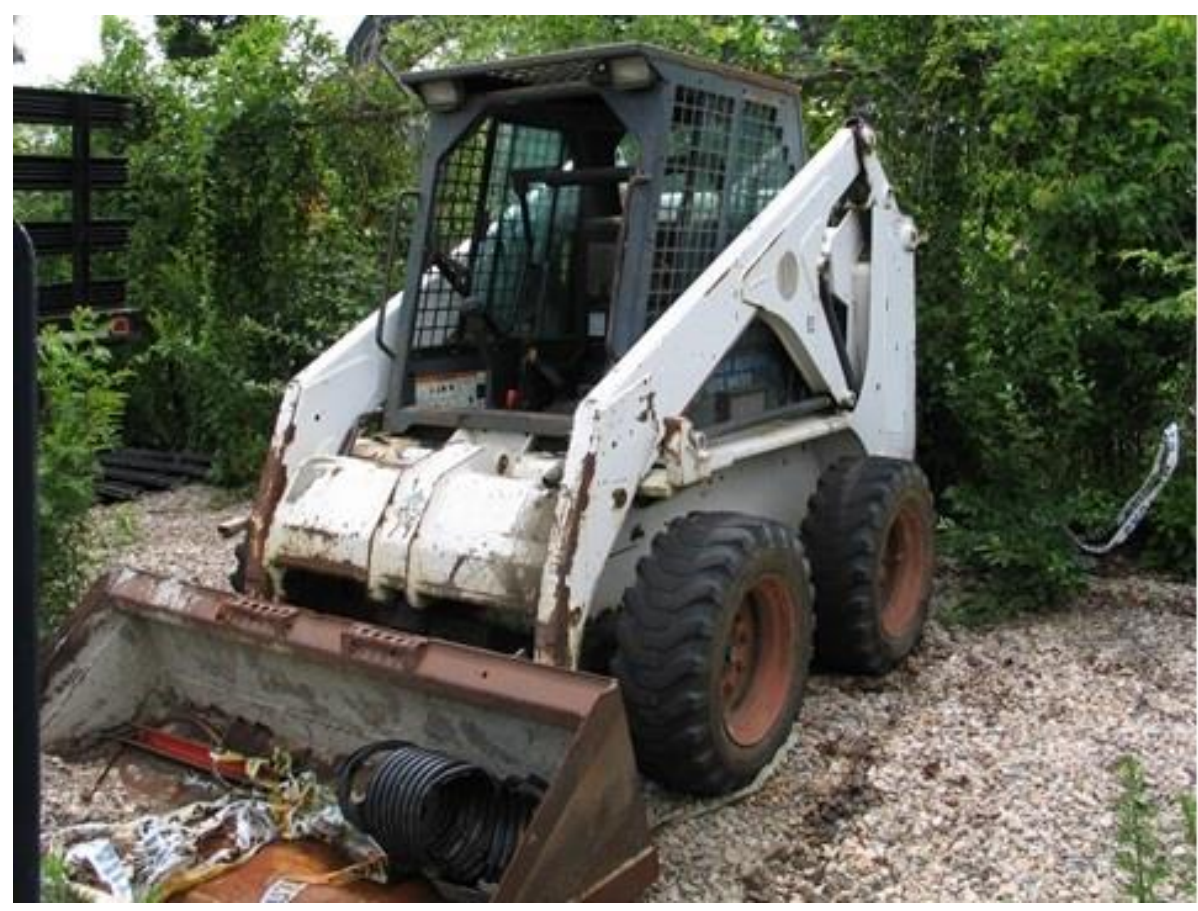

Figure 4 - Skid-steer loader's seat bar and lever controls

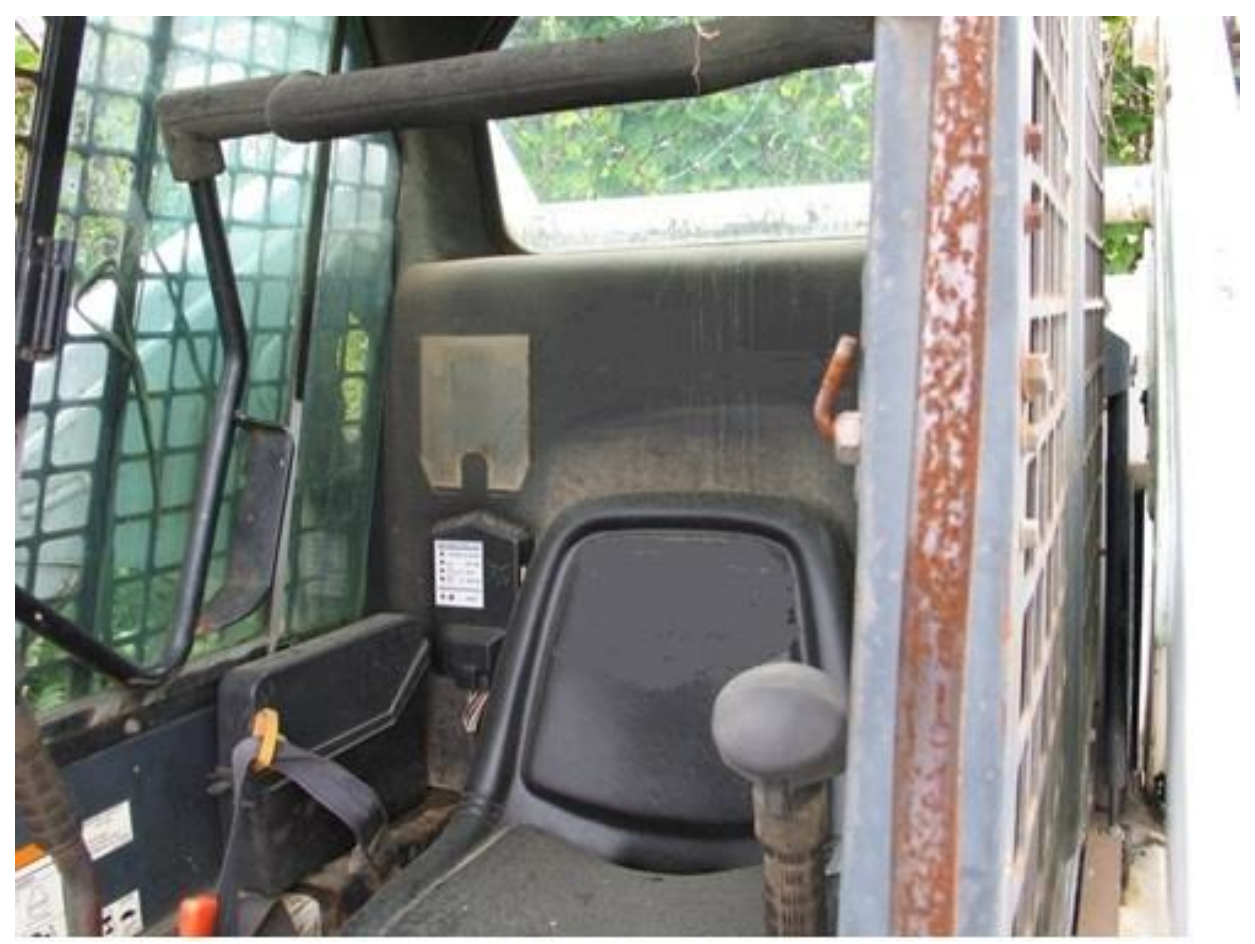


Figure 5 - Skid-steer loader's decal showing the lift arm support

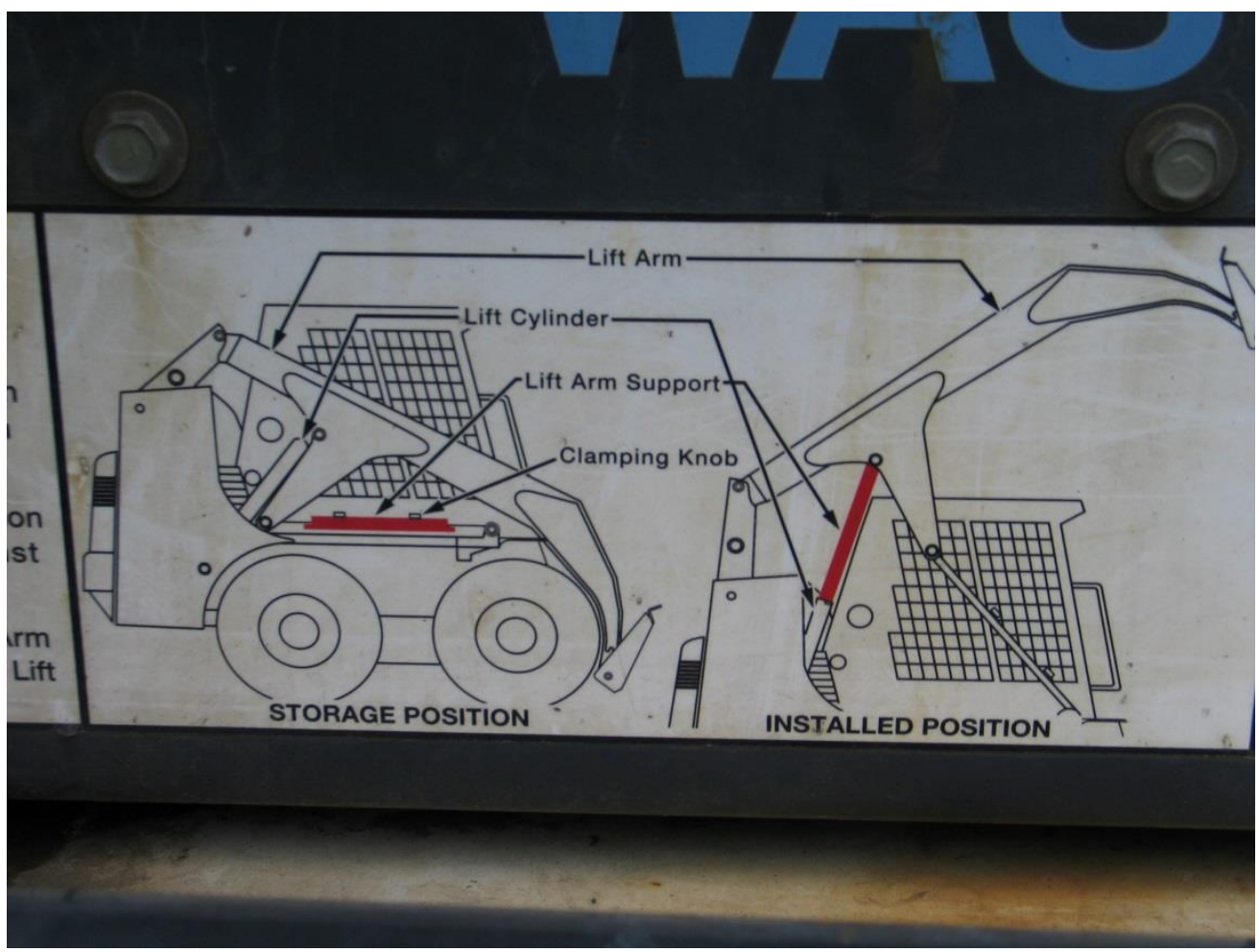




\section{OSHAFFactSheet}

\section{Injury and IIIness Prevention Programs}

Injury and IIIness Prevention Programs are proactive processes that can substantially reduce the number and severity of workplace injuries and illnesses and can alleviate the associated financial burdens on U.S. workplaces. These systematic programs allow employers and workers to collaborate on an ongoing basis to find and fix workplace hazards before workers are hurt or become ill. This Fact Sheet describes some common program elements and how to implement them.

Injury and IIIness Prevention Programs are an effective tool for reducing occupational injuries, illnesses and fatalities. Many workplaces have already adopted such approaches, for example, as part of OSHA's Voluntary Protection Programs (VPP) and Safety and Health Achievement Recognition Program (SHARP) for small employers. Not only do these workplaces experience significant decreases in workplace injuries, but they often report a transformed workplace culture that can lead to higher productivity and quality, reduced turnover, reduced costs and greater worker satisfaction.

Thirty-four states and many nations around the world already require or encourage employers to implement similar programs. Based on the positive experience of these employers, OSHA believes that Injury and IIIness Prevention Programs can provide the foundation for breakthrough changes in the way employers and their workers identify and control hazards, leading to a significantly improved workplace health and safety environment. Adoption of an Injury and IIIness Prevention Program will result in workers suffering fewer injuries, illnesses and fatalities. In addition, employers will improve their compliance with existing standards and experience the financial benefits of a safer and healthier workplace.

Injury and IIIness Prevention Programs should include the systematic identification, evaluation and prevention or control of general workplace hazards and the hazards of specific jobs and tasks.
The major elements of an effective program include:

\section{Management Leadership}

- Establish clear safety and health goals for the program and define the actions needed to achieve those goals.

- Designate one or more individuals with overall responsibility for implementing and maintaining the program.

- Provide sufficient resources to ensure effective program implementation.

\section{Worker Participation}

- Consult with workers in developing and implementing the program and involve them in updating and evaluating the program.

- Include workers in workplace inspections and incident investigations.

- Encourage workers to report concerns, such as hazards, injuries, illnesses and near misses.

- Protect the rights of workers who participate in the program.

\section{Hazard Identification and Assessment}

- Identify, assess and document workplace hazards by soliciting input from workers, inspecting the workplace and reviewing available information on hazards.

- Investigate injuries and illnesses to identify hazards that may have caused them.

- Inform workers of the hazards in the workplace. 


\section{Hazard Prevention and Control}

- Establish and implement a plan to prioritize and control hazards identified in the workplace.

- Provide interim controls to protect workers from any hazards that cannot be controlled immediately.

- Verify that all control measures are implemented and are effective.

- Discuss the hazard control plan with affected workers.

\section{Education and Training}

- Provide education and training to workers in a language and vocabulary they can understand to ensure that they know:

- Procedures for reporting injuries, illnesses and safety and health concerns.

- How to recognize hazards.

- Ways to eliminate, control or reduce hazards.

- Elements of the program.

- How to participate in the program.

- Conduct refresher education and training programs periodically.

\section{Program Evaluation and Improvement}

- Conduct a periodic review of the program to determine if it has been implemented as designed and is making progress towards achieving its goals.

- Modify the program, as necessary, to correct deficiencies.

- Continuously look for ways to improve the program.

For more information, visit the Injury and IIIness Prevention Program page on OSHA's website at: www.osha.gov/dsg/topics/safetyhealth.

Twenty-seven states operate their own occupational safety and health programs approved by OSHA. States enforce similar standards that may have different or additional requirements. A list of state plans is available at www.osha.gov/dcsp/osp.

This OSHA fact sheet is available at: www.osha.gov/Publications/OSHA3665.pdf 
Michael A. Fiore, MS, Director

Massachusetts FACE Program

Occupational Health Surveillance Program

Massachusetts Department of Public Health
Letitia Davis, Sc.D., Ed.M., Director

Occupational Health Surveillance Program

Massachusetts Department of Public Health

$* * * * * * * * * * * * * * * * * * * * * * * * * * * * * * * * * * * * * * * * * * * * * * * * * * * * * * * * * * * * * * * * * * * * * * * * * * * * * * * *$

\section{FATALITY ASSESSMENT AND CONTROL EVALUATION PROGRAM}

The Massachusetts Department of Public Health, in cooperation with the National Institute for Occupational Safety and Health (NIOSH), conducts investigations on the causes of work-related fatalities. The goal of this program, known as Massachusetts Fatality Assessment and Control Evaluation (Massachusetts FACE) is to prevent future fatal workplace injuries. Massachusetts FACE aims to achieve this goal by identifying and studying the risk factors that contribute to workplace fatalities, by recommending intervention strategies, and by disseminating prevention information to employers and employees.

Massachusetts FACE also collaborates with engineering and work environment faculty at the University of Massachusetts at Lowell to identify technological solutions to the hazards associated with workplace fatalities.

NIOSH funded state-based FACE Programs currently include: California, Iowa, Kentucky, Massachusetts, Michigan, New Jersey, New York, Oregon, and Washington.

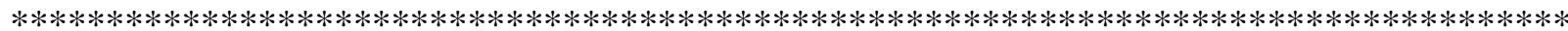

Additional information regarding this report is available from:

Occupational Health Surveillance Program

Massachusetts Department of Public Health

250 Washington Street, 6th floor

Boston, Massachusetts 02108-4619

(617) 624-5627

\section{Evaluate this report}

We would appreciate your feedback on these reports so we may continue to improve the MA FACE project and our investigation reports. A feedback form can be found at:

www.mass.gov/eohhs/docs/dph/occupational-health/report-evaluation.doc

The completed form may be returned by fax to (617) 624-5676, by mail to FACE, 250 Washington

Street, $6^{\text {th }}$ Floor, Boston, MA 02108, or by email to ma.face@ state.ma.us. 